\title{
The prevalence of rheumatic diseases in the elderly in developed countries and its evolution over time
}

\author{
Submitted: 13 October 2003 \\ Accepted: 8 October 2004
}

Summary

Objectives: This study aims at evaluating the prevalence of rheumatic diseases in the elderly and its evolution over time.

Methods: We present a systematic international literature review of the prevalence of rheumatic diseases in the elderly and its evolution over time.

Results: The estimated current prevalence of rheumatic diseases among people aged 65 and more varies between $41 \%$ and $53 \%$, and is similar to estimated prevalence rates in studies performed before 1990 (35-55\%). The prevalence is high and seems to increase rapidly with age. Furthermore, women suffer more frequently from rheumatic diseases than men.

Conclusion: The selected studies included a large range of methods, making comparisons difficult. However, estimates of the prevalence of rheumatic diseases in the elderly appear to be homogeneous in different countries and stable since 1980.

Keywords: Rheumatic diseases - Prevalence - Evolution - Elderly Health - Review.

Chronic diseases, such as cancers, heart diseases, and rheumatic diseases have become a new challenge for public health, since the former major problem, mortality due to infectious diseases, largely declined in the last century. Such diseases affect an increasing population of elderly reaching an increasingly advanced age (Blanc et al. 1995). Among pathologies affecting the elderly, rheumatic diseases are particularly frequent. Being the first cause of disability, they have a pronounced impact on the quality of life, they can be painful, and they are at the origin of functional troubles and deformations (CDC 1995; 1999; Raina et al. 1998). Despite their importance, few systematic studies of their epidemiology in the elderly have been conducted in the international literature. The aims of our study were to determine the current prevalence of rheumatic diseases in the elderly in different developed countries, to identify possible regional differences, and to study the evolution of the prevalence over time based on a systematic literature review.

\section{Methods}

We defined rheumatic diseases by their symptoms (i.e., pain and mobility limitation) rather than by rigorous diagnostic criteria (i.e., validation by health professionals) since most population-based epidemiological data rely on self-reported symptoms from health surveys. Self-reports do not permit differentiation between the various types of rheumatic diseases. First, we studied the prevalence rates of rheumatic diseases found in surveys conducted between 1990 and 2002, which we have considered as the "current prevalence". We did not limit our research to a specific period of prevalence. Second, we studied the evolution of prevalence rates over time. For this purpose, we used epidemiological surveys of rheumatic diseases conducted before 1990 and compared their results with the estimated current prevalences.

We excluded surveys conducted in developing countries for the following reasons: (1) Socio-economic conditions in those countries are not comparable with those found in industrial countries (Adebajo 1990); (2) The main rheumatic diseases are different in developing countries; some are characteristic of these countries, such as the acute tropical polyarthritis, the tuberculous arthritis, or the rheumatic fever; (3) Many studies in developing countries have been conducted in samples that were not representative of the general 
population, but of the rural or urban residents (Adebajo 1990).

To obtain a large sample of publications for our epidemiological survey, we used the selection expression "musculoskeletal diseases OR rheumatic diseases OR arthritis OR rheumatism OR rheumatic complaints OR chronic diseases OR chronic conditions" in the Medline database (1966-2002), and retrieved 83240 articles. We further restricted our selection criteria by forcing the inclusion of the words "prevalence", "epidemiology", "burden of disease" or "time trends" to appear. We obtained 2734 articles published from 1990 to 2002, and 835 articles published before 1990 .

We also found articles by using the terms "rheumatic diseases" and "musculoskeletal diseases" in the Cochrane Library, on the websites of the American Medical Association (http://www.ama-assn.org), National Center of Health Statistics (http://search.cdc.gov), and American Geriatrics Society (http://www.americangeriatrics.org), and finally on the Internet with the research tool Google (http://www.google. ch). Some additional publications found in the references section of articles selected above were used as well.

We then selected articles based on their title and abstract, and read every article that measured the prevalence of rheumatic diseases. We kept all population-based surveys (general health surveys, as well as specific epidemiological surveys with samples representative of the country population) published in English, French, and German that used our definition. Eventually, 14 articles for the current prevalence and 16 for the prevalence before 1990 were retained. The results of this paper are based on these 30 articles.

One of the major problems faced in this review was that definitions and methods were not uniform in the various studies. For example, it was often unclear whether acute diseases or post-trauma joint pain had been included. Given these unclear points, we decided to include all the studies with self-reported symptoms of rheumatic diseases, but to separate them so that we can discuss the possible impact of these unclear points. We therefore decided to assume the following: (1) When rheumatic diseases had been defined on the basis of symptoms lasting more than six weeks or defined as rheumatisms, acute diseases and trauma had likely been excluded. (2) When complaints in the preceding four weeks had been taken in consideration, acute diseases and trauma had been likely included. (3) When arthritis had been taken into consideration without any period of prevalence, acute diseases had been likely included. (4) When not mentioned, persons in institutions had been likely included.

\section{Results}

Estimations of the current prevalence of rheumatic diseases for people aged 65 and older varied between $41 \%$ and $53 \%$ (Badley et al. 1994; CDC 1994; 2000; van den Bos 1995; Lawrence et al. 1998; Desai et al. 1999; Laiho et al. 2001; Tab. 1). One study obtained a higher prevalence, despite the use of a severity criterion to define rheumatic diseases (pain lasting more than one week; Ballina Garcia et al. 1994). The authors explained the difference by the fact that the interview had been conducted by a rheumatologist. They mentioned a study by Allander et al. (1973) that showed that interviews conducted by non-physicians tended to lead to an underestimated prevalence. Ballina Garcia et al. (1994) also suggested environmental and socio-cultural reasons. Only one study, conducted in the United States in 1995-96

Table 1 Estimates of current prevalence for people aged 65 and more

\begin{tabular}{|c|c|c|c|c|c|c|c|c|}
\hline \multirow[t]{2}{*}{ Date and location of survey } & \multirow[t]{2}{*}{$\begin{array}{l}\text { Period of prevalence } \\
\text { [months] }\end{array}$} & \multirow[t]{2}{*}{ Age [yr] } & \multicolumn{4}{|c|}{$\begin{array}{l}\text { Particularities of } \\
\text { definition, subjects, etc. }\end{array}$} & \multirow[t]{2}{*}{$\begin{array}{l}\text { Prevalence } \\
{[\%]}\end{array}$} & \multirow[t]{2}{*}{ Ref } \\
\hline & & & \#S & A & $\mathbf{T}$ & I & & \\
\hline 1996-98, USA & 12 & $\geq 65$ & $\mathrm{~N} / \mathrm{A}$ & + & + & - & $53(52-55)^{\mathrm{a}}$ & 1 \\
\hline 1995-96, USA & 12 & $\geq 65$ & $\sim 31,497$ & + & + & - & $\begin{array}{l}49 \\
M: 41 \mathrm{~W}: 55\end{array}$ & 2 \\
\hline 1993-94, Amsterdam, NL & N/A & $55-79$ & 9,998 & + & + & + & 47 & 3 \\
\hline 1989-91, USA & 12 & $\geq 65$ & $\sim 31,190$ & + & + & - & 49 & $4 ; 5$ \\
\hline 1990, Ontario, CA & N/A & $\geq 65$ & $\mathrm{~N} / \mathrm{A}$ & - & - & $\mathrm{N} / \mathrm{A}$ & 43 & 6 \\
\hline 1990, Asturies, E & 12 & $\geq 65$ & $\sim 37$ & + & + & - & 68 & 7 \\
\hline 1989-90, Helsinki \& Vantaa, SF & N/A & $\geq 65$ & 1,317 & + & + & - & 41 & 8 \\
\hline
\end{tabular}

$\mathrm{M}=$ men; $\mathrm{W}=$ women; $\# \mathrm{~S}=$ number of subjects in the age range of interest.; + = included; $-=$ excluded; $\mathrm{A}=$ acute diseases; $\mathrm{T}=$ trauma, $\mathrm{I}=$ institutionalized persons; N/A = not available, ref $=$ references

$\sim$ Indicates that the total number of participants as been calculated based on the number of affected participants and the prevalence

a Only study with $95 \% \mathrm{Cl}$

References: (1) CDC (2000); (2) Desai et al. (1999); (3) van den Bos (1995); (4) Lawrence et al. (1998); (5) CDC (1994); (6) Badley et al. (1994); (7) Ballina

Garcia et al. (1994); (8) Laiho et al. (2001) 
The prevalence of rheumatic diseases in the elderly in developed

countries and its evolution over time

Table 2 Range of current prevalence estimates measured in studies by age and period of prevalence, for both genders

\begin{tabular}{|c|c|c|c|c|c|c|c|c|c|}
\hline \multirow[t]{2}{*}{ Sex } & \multirow[t]{2}{*}{ Period of prevalence } & \multicolumn{2}{|c|}{$65-74$ yr old } & \multicolumn{2}{|c|}{$75-84$ yr old } & \multicolumn{2}{|c|}{$\geq 75$ yr old } & \multicolumn{2}{|c|}{$\geq 85 \mathrm{yr}$ old } \\
\hline & & Prev [\%] & Ref & Prev [\%] & Ref & Prev [\%] & Ref & Prev [\%] & Ref \\
\hline \multirow[t]{6}{*}{ Men } & altogether & $40-44$ & $1-5$ & $46-47$ & $1 ; 4$ & $40-50$ & $2 ; 3 ; 5$ & $42-47$ & $1 ; 4 ; 6$ \\
\hline & point & 44 & 3 & - & - & 50 & 3 & - & - \\
\hline & 4 weeks & - & - & - & - & - & - & 47 & 6 \\
\hline & 12 months & 44 & 1 & 46 & 1 & - & - & 42 & 1 \\
\hline & lifetime & 40 & 5 & - & - & 44 & 5 & - & - \\
\hline & N/A & $36-41$ & $2 ; 4$ & 47 & 4 & 40 & 2 & 44 & 4 \\
\hline \multirow[t]{6}{*}{ Women } & altogether & $46-59$ & $1-5$ & $56-61$ & $1 ; 4$ & $52-66$ & $2 ; 3 ; 5$ & $60-63$ & $1 ; 4 ; 6$ \\
\hline & point & 56 & 3 & - & - & 66 & 3 & - & - \\
\hline & 4 weeks & - & - & - & - & - & - & 62 & 6 \\
\hline & 12 months & 52 & 1 & 61 & 1 & - & - & 63 & 1 \\
\hline & lifetime & 54 & 5 & - & - & 60 & 5 & - & - \\
\hline & $\mathrm{N} / \mathrm{A}$ & $46-59$ & $2 ; 4$ & 56 & 4 & 52 & 2 & 59 & 4 \\
\hline Men and & altogether & $42-51$ & $2 ; 3 ; 7 ; 8$ & 55 & $8 ; 9$ & $48-59$ & $2 ; 3 ; 7$ & 57 & $6 ; 8$ \\
\hline Women & point & - & - & - & - & 59 & 3 & - & - \\
\hline \multirow{4}{*}{ together } & 4 weeks & 51 & 3 & - & - & - & - & 57 & 6 \\
\hline & 12 months & 45 & $7 ; 8$ & 55 & $8 ; 9$ & 55 & 7 & 57 & 8 \\
\hline & lifetime & - & - & - & - & - & - & - & - \\
\hline & N/A & 42 & 2 & - & - & 48 & 2 & - & - \\
\hline
\end{tabular}

Legend: Prev = Prevalence; N/A = not available; Ref = references; References: (1) CDC (2001); (2) Badley et al. (1995); (3) Badley \& Wang (1998); (4) March et al. (1998); (5) Parker et al. (1997); (6) van Schaardenburg et al. (1994); (7) Desai et al. (1999); (8) CDC (1994); (9): Lawrence et al. (1998)

Table 3 Prevalence estimates for people aged 65 and more in studies conducted before 1990

\begin{tabular}{|c|c|c|c|c|c|c|c|c|}
\hline \multirow[t]{2}{*}{ Date and location of survey } & \multirow[t]{2}{*}{ Period of prevalence } & \multirow[t]{2}{*}{ Age [yr] } & \multicolumn{4}{|c|}{ Definition, subjects. } & \multirow[t]{2}{*}{ Prevalence [\%] } & \multirow[t]{2}{*}{ Ref } \\
\hline & & & \#S & A & $\mathbf{T}$ & $\mathbf{I}$ & & \\
\hline 1986, Cardiff, UK & $\begin{array}{l}\text { a) point } \\
\text { b) lifetime }\end{array}$ & $\begin{array}{l}\geq 65 \\
\geq 65\end{array}$ & $\begin{array}{l}712 \\
712\end{array}$ & $\begin{array}{l}+ \\
+\end{array}$ & $\begin{array}{l}+ \\
+\end{array}$ & $\begin{array}{l}+ \\
+\end{array}$ & $\begin{array}{l}\text { M: } 41 \text { W: } 49 \\
\text { M: } 57 \text { W: } 72\end{array}$ & $\begin{array}{l}1 \\
1\end{array}$ \\
\hline 1986, NL & $\mathrm{N} / \mathrm{A}$ & $\geq 65$ & $\mathrm{~N} / \mathrm{A}$ & - & - & N/A & 35 & 2 \\
\hline $1985, \mathrm{~s}$ & $12 \mathrm{mo}$ & $50-70$ & 900 & \multicolumn{2}{|c|}{ sympt. $\geq 6$ wk } & + & $37.8(33.3-42.3)^{\mathrm{a}}$ & 3 \\
\hline 1984, USA & $\begin{array}{l}\text { a) } 12 \mathrm{mo} \\
\text { b) } 12 \mathrm{mo}\end{array}$ & $\begin{array}{l}\geq 60 \\
\geq 70\end{array}$ & $\begin{array}{l}13,807 \\
13,807\end{array}$ & $\begin{array}{l}+ \\
+\end{array}$ & - & - & $\begin{array}{l}49 \\
55\end{array}$ & $\begin{array}{l}4 ; 5 \\
4 ; 5\end{array}$ \\
\hline $\begin{array}{l}\text { 1983-85, USA } \\
\sim 1983-84, \text { Aberdeen, UK }\end{array}$ & $\begin{array}{l}12 \mathrm{mo} \\
\mathrm{N} / \mathrm{A}\end{array}$ & $\begin{array}{l}\geq 65 \\
\geq 60\end{array}$ & $\begin{array}{l}N / A \\
619\end{array}$ & $\begin{array}{l}+ \\
+\end{array}$ & $\begin{array}{l}- \\
+\end{array}$ & - & $\begin{array}{l}\text { M: } 38 \text { W: } 54 \\
36\end{array}$ & $\begin{array}{l}6 \\
7\end{array}$ \\
\hline $1982, \mathrm{D}$ & 4 weeks & $\geq 65$ & $\mathrm{~N} / \mathrm{A}$ & + & + & + & $\sim 8$ & 8 \\
\hline 1978-79, CA & N/A & $\geq 65$ & 2,019 & + & + & N/A & $\begin{array}{l}48 \\
\text { M: } 39 \text { W: } 56\end{array}$ & 9 \\
\hline $1976, \mathrm{SF}$ & $\mathrm{N} / \mathrm{A}$ & $\geq 54$ & $\mathrm{~N} / \mathrm{A}$ & - & - & + & M: 28 W: 36 & 10 \\
\hline 1971-72, Goteborg, S & lifetime & $\geq 70$ & $\mathrm{~N} / \mathrm{A}$ & \multicolumn{2}{|c|}{ every week } & + & M: 32 W: 56 & 11 \\
\hline $1970-71, \mathrm{~F}$ & N/A & $\geq 65$ & $\mathrm{~N} / \mathrm{A}$ & - & - & N/A & $\sim 50$ & 12 \\
\hline 1959-60, Tecumseh, USA & lifetime & $\geq 70$ & 289 & + & + & + & M: 45 W: 64 & 13 \\
\hline
\end{tabular}

\#S = number of subjects in the age range of interest; + = included; $-=$ excluded; $\mathrm{A}=$ acute diseases; $\mathrm{T}=$ trauma; $\mathrm{I}=$ institutionalized persons; $\mathrm{M}$ : men, W: women; N/A = not available. References: (1) Vetter et al (1990), (2) Valkenburg (1988), (3) Jacobsson et al (1989), (4) Yelin (1992), (5) Guralnik et al (1989), (6) Verbrugge et al (1995), (7) Taylor et al. (1984), (8) Moser et al (1986), (9) Lee et al. (1985), (10) Klaukka et al. (1982), (11) Svanborg (1978), (12) Moser et al. (1986) and (13) Mikkelsen et al. 1967)

a sole study that reports a $95 \% \mathrm{Cl}$

(Desai et al. 1999), measured the prevalence for both genders: prevalence estimates were significantly higher for women (55\%) than for men (41\%).

Table 2 summarizes a set of studies emphasizing the variation of the prevalence estimates as a function of the age class and period of prevalence, for both sexes. It suggests that prevalence rates increase with age, for both sexes, as the range of published prevalence estimates is generally higher in the oldest age groups.

The estimated current prevalence rates for people older than 65 are similar to the estimated prevalence rates in studies performed before $1990(35 \%-55 \%)$ (Taylor \& Ford 
Table 4 Range of prevalence estimates measured in studies conducted before 1990, by age and period of prevalence, for both genders

\begin{tabular}{|c|c|c|c|c|c|c|c|}
\hline \multirow[t]{2}{*}{ Sex } & \multirow[t]{2}{*}{ Period of prevalence } & \multicolumn{2}{|c|}{$\geq 65 \mathrm{yr}$ old } & \multicolumn{2}{|c|}{$\geq 65-74$ yr old } & \multicolumn{2}{|c|}{$\geq 75 \mathrm{yr}$ old } \\
\hline & & $\mathrm{P}[\%]$ & Ref & $\mathbf{P}[\%]$ & Ref & $\mathbf{P}[\%]$ & Ref \\
\hline \multirow[t]{6}{*}{ Men } & altogether & $28-57$ & $1-5$ & $22-58$ & $2 ; 6-8$ & $29-67$ & $2 ; 5 ; 6 ; 9$ \\
\hline & point & 41 & 2 & $22-39$ & $2 ; 7 ; 8$ & $32-50$ & 2 \\
\hline & 4 weeks & - & - & - & - & - & - \\
\hline & 12 months & - & - & - & - & - & - \\
\hline & lifetime & $31-57$ & $2 ; 4 ; 5$ & $55-58$ & 2 & $30-67$ & $2 ; 5 ; 9$ \\
\hline & N/A & $28-39$ & $1 ; 3$ & 37 & 6 & 29 & 6 \\
\hline \multirow[t]{6}{*}{ Women } & altogether & $34-72$ & $1-5$ & $26-73$ & $2 ; 6-8$ & $42-79$ & $2 ; 5 ; 6 ; 9$ \\
\hline & point & 49 & 2 & $26-52$ & $2 ; 7 ; 8$ & $42-55$ & 2 \\
\hline & 4 weeks & - & - & - & - & - & - \\
\hline & 12 months & - & - & - & - & - & - \\
\hline & lifetime & $34-72$ & $2 ; 4 ; 5$ & $72-73$ & 2 & $62-79$ & $2 ; 5 ; 9$ \\
\hline & N/A & $36-56$ & $1 ; 3$ & 58 & 6 & 59 & 6 \\
\hline Men and & altogether & $35-$ & $1 ; 6,10 ; 11-15$ & $40-47$ & $16-18$ & $52-70$ & $16 ; 17 ; 19$ \\
\hline Women & point & $55^{*}$ & - & - & - & - & - \\
\hline \multirow[t]{5}{*}{ together } & 4 weeks & - & 10 & - & - & - & - \\
\hline & 12 months & 8 & $11-14$ & 47 & $16 ; 17$ & 52 & $16 ; 17$ \\
\hline & lifetime & $38-55$ & - & 40 & 18 & - & - \\
\hline & $N / A$ & - & $1 ; 6 ; 10 ; 15$ & - & - & 70 & 19 \\
\hline & & $35-50$ & & & & & \\
\hline
\end{tabular}

$\mathrm{P}=$ prevalence, ref $=$ references, $\mathrm{N} / \mathrm{A}=$ not available

* one study obtained a result of $8 \%$ for this category (21), but considered only the serious conditions. We do not use this value in this review. References: (1) Lee et al. (1985), (2) Vetter et al. (1990), (3) Klaukka et al. (1982), (4) Svanborg (1978), (5) Mikkelsen et al. (1967), (6) Valkenburg (1988), (7) Bjelle et al. (1980), (8) Bjelle \& Allander (1981), (9) Laine (1962), (10) Moser \& Ackermann-Liebrich (1986), (11) Jacobsson et al. (1989), (12) Guralnik et al. (1989), (13) Yelin (1992), (14) Verbrugge \& Patrick (1995), (15) Taylor \& Ford (1984), (16) Lawrence et al. (1989), (17) Collins (1988), (18) Cunningham \& Kelsey (1984) and (19) Ford et al. (1988)

1984; Lee et al. 1985; Moser \& Ackermann-Liebrich 1986; Valkenburg 1988; Jaccobsson et al. 1989; Guralnik et al. 1989; Yelin 1992; Verbrugge \& Patrick 1995; Tab. 3). One survey (Deutscher Mikrozensus 1982), however, obtained a lower prevalence $(8 \%)$ because only severe cases were reported (Moser \& Ackermann-Liebrich 1986). There is no evidence for an evolution over time.

The United States is the only country where sufficient surveys with similar definitions and methods were conducted (Tab. 1 and 3). In this country, the estimated prevalences between 1959 and 1998 ranged between $49 \%$ and $55 \%$ (Tab. 1 and 3) and there is again no evidence for an evolution over time. The trend of increasing prevalence with increasing age is also found in studies previous to 1990 (Tab. 4).

\section{Discussion}

Although many publications refer to the high prevalence of rheumatic diseases in industrialized countries, few studies provide data with sufficient methodological details. In addition, the variety of definitions and methods found in the literature is a serious obstacle to the study of time trends and to international comparison. For instance, many studies consider different periods of prevalence. They may or may not use severity criteria, and include or exclude people suffering from back pain or being hospitalized. When severity criteria are used, the prevalence drops. Our review shows that the inclusion of elderly in institutions does not significantly affect the prevalence, as previously noted by Badley \& Wang (1998). Otherwise the inclusion of acute diseases, trauma or back pain does not seem to affect the prevalence. This result is surprising since, for example, back pain is frequent in the general population (Walker 2000). Furthermore, the review reveals a lack of data for the prevalence of rheumatic diseases in the persons aged 85 and more.

According to our literature review, the various estimates of the current prevalence of rheumatic diseases in the older than 65 are similar (Tab 1): they vary between $41 \%$ and $53 \%$. This similarity suggests that the prevalence is comparable among the studied countries.

Furthermore, our literature review shows that prevalences found after 1990 are similar to those found before that year (Tab. 1 and 3). Indeed, prevalence estimates found before 1990 range between $35 \%$ and $55 \%$, thus showing no evidence for an evolution in time. This stability in time is supported by the similar prevalence rates observed in surveys conducted in the United States between 1959 and 1998 that used comparable definitions and methods for several years (Tab. 1 and 3). In contrast, Miles et al. (1993) found an increase in prevalence over time over earlier decades. They compared the prevalence of rheumatic diseases in population surveys conducted by the National Center of Health 
Statistics in the United States between 1960-62 and 1976-80. After standardisation to the population in 1970, the prevalence was higher in 1976-1980 than in 1960-62, except for people 70-74 years old.

At least three hypotheses could explain the discrepancy between the conclusions of Miles et al. (1993) and ours:

1) The apparent stability of the prevalence estimates in our review does not reflect appropriately the reality. Since our review included several studies in time and in geographical places, we are inclined to believe that this hypothesis is improbable.

2) The Miles et al. study had a too limited sample. Indeed, those authors used only 2 studies and limited their sample to people younger than 74 years old. Since the prevalence of rheumatic diseases diminishes for ages between 70 and 74 in their data, it is possible that the trend reverts after an age of 70 .

3) Health in old age has improved after the end of the 1970s. In our literature review, two studies only have been found before 1980. Six studies were identified between 1983 and 1998 and they reported a prevalence ranging between $49 \%$ and $53 \%$. This strongly suggests that the prevalence has been stable since the 1980s. The study of Miles et al. reveals a possible worsening of health between 1960 and 1970. It does not contradict a possible improvement of health in old age after 1980. This hypothesis is difficult to prove since we lack studies before 1980 .

The majority of the studies incorporated in our review are based on population surveys using data from interviews. In addition to the problems of definition, the reproducibility and the validity of such surveys may be problematic (Cobb et al. 1955; Lawrence 1977; Magi et al 1984; Ford et al. 1988; Beckett et al. 2000). According to Lawrence (1977), Magi et al. (1984) and Cobb et al. (1955), the prevalences obtained through population surveys based on interviews are underestimated. The estimates of the prevalence found in the last 10 years are closer to each other than the earlier prevalences, probably because of improvements in survey methodology.

Despite the limitations described above, since the results of the different studies are similar, we believe that our results are suitable. Probably, the inclusion or exclusion of acute diseases, trauma, and institutionalized persons did not give different results, because (1) the majority of the elderly have chronic rheumatic diseases rather than acute rheumatic dis- eases, (2) part of the trauma by the elderly are linked to subjacent chronic diseases, and (3) the proportion of elderly who are institutionalized is low. We argue that those who did not report their diseases are those whose disease did not interfere mainly with their everyday-life, and consequently they are probably not those in need for health services. Since we were interested in the burden of disease, we believe that our results reflect it appropriately, even if they may underestimate the true prevalence of rheumatic diseases.

\section{Conclusions}

The prevalence of rheumatic diseases appears to be homogeneous in different countries and stable since 1980. Rheumatic diseases are frequent and affect about half the population of people older than 65 .

The homogeneity of the prevalence between countries, at least since 1980, suggests that their populations share the same characteristics in terms of risk factors for rheumatic diseases. In addition, the stability of estimates over time is in favour of a health improvement of elderly people. Indeed, assuming that the health of elderly was stable in time, an increase in the prevalence would be expected, since the frequency of rheumatic diseases seems to increase with age (Tab. 2 and 4) and since the proportion of very old people increases within the elderly.

Epidemiological surveys should use standardized methods with the same definition to facilitate comparisons between countries and in time. Furthermore, reports should systematically mention what is included in the definition of rheumatic diseases (acute diseases, trauma, gout, etc.), the studied period of prevalence and whether persons in institution are included.

In face of the large proportion of the population affected by rheumatic diseases, primary, secondary, and tertiary preventive measures must be taken to decrease the risk of occurrence of rheumatic diseases and to improve the quality of life. Such diseases have, however, no easy treatment. A primary preventive measure could be the elimination of risk factors such as obesity and occupational risk factors.

\section{Acknowledgments}

We thank Nicole Chavaz-Cirilli for her help during our research, Dr Marc Audard, Regina Renner, and Aviva Meyer for a careful reading of the manuscript and useful comments. 
Zusammenfassung

Die Prävalenz rheumatischer Krankheiten bei älteren Menschen und deren Entwicklung

Fragestellung: Ziel dieser Studie ist die Untersuchung der Prävalenz rheumatischer Krankheiten bei Menschen im Alter von über 65 Jahren sowie die Entwicklung in den letzten Jahrzehnten.

Methoden: Wir führten einen systematischen Review der internationalen Literatur zur Prävalenz rheumatischer Krankheiten im Alter durch.

Ergebnisse: Die Einschätzung der gegenwärtigen Prävalenz rheumatischer Erkrankungen im Alter liegt zwischen $41 \%$ und $53 \%$, und entspricht den Ergebnissen der Prävalenzstudien von vor 1990 (35-55\%). Die Prävalenz ist hoch und scheint mit zunehmendem Alter anzusteigen. Weiterhin sind mehr Frauen als Männer betroffen.

Schlussfolgerungen: Trotz einer grossen Auswahl an Methoden, die den Vergleich zwischen verschiedenen Studien erschwert, scheint die Prävalenz rheumatischer Erkrankungen im Alter im internationalen Vergleich homogen und seit 1980 stabil zu sein.

\section{Résumé}

La prévalence des maladies rhumatismales chez les personnes âgées et son évolution dans le temps

Objectifs: Cette étude a pour but d'étudier la prévalence des maladies rhumatismales chez les personnes âgées et son évolution dans le temps.

Méthodes: Une revue de littérature systématique et internationale consacrée à la prévalence des maladies rhumatismales chez les personnes âgées et à son évolution.

Résultats: La prévalence actuelle des maladies rhumatismales chez les personnes âgées de plus de 65 ans est de $41 \%$ à $53 \%$; elle est similaire aux estimations des taux de prévalence trouvés dans les études antérieures à 1990 (35-55\%). La prévalence des maladies rhumatismales est élevée et semble augmenter avec l'âge. De plus, les femmes sont plus fréquemment atteintes de maladies rhumatismales que les hommes.

Conclusions: Les études sélectionnées ont recouru à diverses méthodes, rendant délicate toute comparaison. Cependant, la prévalence des maladies rhumatismales chez les personnes âgées semble être homogène entre pays et stable depuis 1980 .

\section{References \\ Adebajo AO (1990). Rheumatology in the Third World. Ann Rheum Dis 49: 813-6.}

Allander E (1973). Diagnostic process and rheumatic disease. Scand J Soc Med 3: 145-53.

Badley EM, Rasooly I, Webster GK (1994). Relative importance of musculoskeletal disorders as a cause of chronic health problems, disability, and health care utilization: findings from the 1990 Ontario Health Survey. J Rheumatol 21: 505-14.

Badley EM, Webster GK, Rasooly I (1995). The impact of musculoskeletal disorders in the population: are they just aches and pains? Findings from the 1990 Ontario Health Survey. J Rheumatol 22: 733-9.

Badley EM, Wang PP (1998). Arthritis and the aging population: projections of arthritis prevalence in Canada 1991 to 2031. J Rheumatol 25: 138-44.
Ballina Garcia FJ, Hernandez Mejia R, Martin Lascuevas P, Fernandez Santana J, Cueto Espinar A (1994). Epidemiology of musculoskeletal complaints and use of health services in Asturias, Spain. Scand J Rheumatol 23: 137-41.

Beckett M, Weinstein M, Goldman N, Yu-Hsuan $L$ (2000). Do health interview surveys yield reliable data on chronic illness among older respondents? Am J Epidemiol 151: 315-23.

Bjelle A, Allander E, Magi M (1980). Rheumatic disorders in the Swedish population and health care system. J Rheumatol 7: 877-85.

Bjelle A, Allander E (1981). Regional distribution of rheumatic complaints in Sweden. Scand J Rheumatol 10: 9-15

Blanc O, Höpflinger F, Joye D, Schuler M (1995) Recensement fédéral de la population 1990: la population en Suisse: structure et dynamique spatiale. Berne: OFS

van den Bos GAM (1995). The burden of chronic diseases in terms of disability, use of health care and healthy life expectancies. Eur J Public Health 5: 29-34.
CDC, Centers for Diseases Control and Prevention (1994). Arthritis prevalence and activity limitations, United States, 1990. MMWR Morb Mortal Wkly Rep 43: 433-8.

CDC, Centers for Disease Control and Prevention (1998). Health-related quality of life and activity limitation, eight states, 1995. MMWR Morb Mortal Wkly Rep 47: 134-40.

CDC, Centers for Disease Control and Prevention (2000). Health-related quality of life among adults with arthritis: behavioral risk factor surveillance system, 11 states, 1996-1998. MMWR Morb Mortal Wkly Rep 49: 366-9.

CDC, Centers for disease Control and Prevention (2001). Prevalence of disabilities and associated health conditions among adults, United States, 1999. MMWR Morb Mortal Wkly Rep 50: 120-5.

CDC, Centers for Disease Control and Prevention (2001). Prevalence of arthritis-United States, 1997. MMWR Morb Mortal Wkly Rep 50: 334-6.

Cobb S, Thompson DJ, Rosenbaum J, Warren JE, Merchant WR (1955). On the measurement of prevalence of arthritis and rheumatism from interview data. J Chronic Dis 3: 134-9. 
Collins JG (1988). Prevalence of selected chronic conditions, United States, 1983-85. Adv Data 155: $1-16$.

Cunningham LS, Kelsey JL (1984). Epidemiology of musculoskeletal impairments and associated disability. Am J Public Health 74: 574-9.

Desai MM, Zhang P, Hennessy CH (1999). Surveillance for morbidity and mortality among older adults - United States, 1995-1996. Morb Mortal Wkly Rep CDC Surveill Summ 48: 7-25. Ford AB, Folmar SJ, Salmon RB, Medalie JH, Roy AW, Galazka SS (1988). Health and function in the old and very old. J Am Geriatr Soc 36: 187-97.

Guralnik JM, LaCroix AZ, Everett DF, Kovar $M G$ (1989). Aging in the eighties: the prevalence of comorbidity and its association with disability. Adv Data 170:1-8.

Jacobsson L, Lindgarde F, Manthorpe R (1989). The commonest rheumatic complaints of over six weeks' duration in a twelve-month period in a defined Swedish population: prevalences and relationships. Scand J Rheumatol 18: 353-60.

Klaukka T, Sievers K, Takala J (1982). Epidemiology of rheumatic diseases in Finland in 1964-76. Scand J Rheumatol Suppl 47: 5-13.

Laiho K, Tuomilehto J, Tilvis R (2001). Prevalence of rheumatoid arthritis and musculoskeletal diseases in the elderly population. Rheumatol Int 20: 85-7.

Laine VAI (1962). Rheumatic complaints in an urban population in Finland. Acta Rheumatol Scand 8: 81-8.

Lawrence JS (1977). Rheumatism in populations. London: W. Heinimann.

Lawrence RC, Hochberg MC, Kelsey JL, McDuffie FC, Medsger TAJ, Felts WR (1989). Estimates of the prevalence of selected arthritic and musculoskeletal diseases in the United States. J Rheumatol 16: 427-41.
Lawrence RC, Helmick CG, Arnett FC, et al. (1998). Estimates of the prevalence of arthritis and selected musculoskeletal disorders in the United States. Arthritis Rheum 41: 778-99.

Lee P, Helewa A, Smythe HA, Bombardier C, Goldsmith CH (1985). Epidemiology of musculoskeletal disorders (complaints) and related disability in Canada. J Rheumatol 12: 1169-73.

Magi M, Allander E, Bjelle A, Ragnarsson A (1984). Rheumatic disorders in a health survey: how valid and reliable are the reports? Scand J Soc Med 12: 141-6.

March LM, Brnabic AJ, Skinner JC, Schwarz JM, Finnegan T, Druce J (1998). Musculoskeletal disability among elderly people in the community. Med J Aust 168: 439-42.

Mikkelsen WM, Dodge HJ, Duff IF, Kato H (1967). Estimates of the prevalence of rheumatic diseases in the population of Tecumseh, Michigan, 1959-60. J Chronic Dis 20:351-69.

Miles TP, Flegal K, Harris T (1993). Musculoskeletal disorders: time trends, comorbid conditions, self-assessed health status, and associated activity limitations. Vital Health Stat $327: 275-88$.

Moser HP, Ackermann-Liebrich U (1986). Die Epidemiologie rheumatischer Erkrankungen in der Schweiz und angrenzenden Ländern. Basel: Roche.

Parker CJ, Morgan K, Dewey ME (1997). Physical illness and disability among elderly people in England and Wales: the Medical Research Council Cognitive Function and Ageing Study. The Analysis Group. J Epidemiol Community Health 51: 494-501.

Raina P, Dukeshire S, Lindsay J, Chambers LW (1998). Chronic conditions and disabilities among seniors: an analysis of population-based health and activity limitation surveys. Ann Epidemiol 8: 402-9. van Schaardenburg D, van den Brande KJS, Ligthart GJ, Breedveld FC, Hazes JM (1994). Musculoskeletal disorders and disability in persons aged 85 and over: a community survey. Ann Rheum Dis 53: 807-11.

Svanborg A (1978). Seventy-year-old people in Gothenburg: a population study in an industrialized Swedish city. II. General presentation of social and medical conditions. Acta Med Scand suppl 611: 1-37.

Taylor R, Ford G (1984). The chief scientist reports ... Arthritis/rheumatism in an elderly population: prevalence and service use. Health Bull (Edinb) 42: 274-81.

Yelin E (1992). Arthritis: the cumulative impact of a common chronic condition. Arthritis Rheum 35: 489-97.

Valkenburg HA (1988). Epidemiologic considerations of the geriatric population. Gerontology 34 (Suppl 1): 2-10.

Verbrugge LM, Patrick DL (1995). Seven chronic conditions: their impact on US adults' activity levels and use of medical services. Am J Public Health 85: 173-82.

Vetter NJ, Charny M, Lewis PA, Farrow S (1990). Prevalence and treatment of symptoms of rheumatism and arthritis among over 65 year olds: a community profile. Br J Gen Pract 40: 69-71.

Walker BF (2000). The prevalence of low back pain: a systematic review of the literature from 1966 to 1998 . J Spinal Disord 1: 205-17.

Address for correspondence

Marjorie M. Mariller, MD

601 West 115th Street \#127,

New York, NY 10025

USA

Tel.: +1 2127495016

e-mail: mmm2127@columbia.edu 